\title{
Detection and management of arrhythmias in peripartum cardiomyopathy
}

\author{
Julian Hoevelmann $^{1,2 \#}$, Lina Hähnle ${ }^{1 \#}$, Julia Hähnle ${ }^{1}$, Karen Sliwa ${ }^{1,3}$, Charle Viljoen ${ }^{1,3}$ \\ ${ }^{1}$ Hatter Institute for Cardiovascular Research in Africa, University of Cape Town, Cape Town, South Africa; ${ }^{2}$ Department of Cardiology and \\ Angiology, Hannover Medical School, Hannover, Germany; ${ }^{3}$ Division of Cardiology, University of Cape Town, Cape Town, South Africa \\ Contributions: (I) Conception and design: All authors; (II) Administrative support: None; (III) Provision of study materials or patients: None; (IV) \\ Collection and assembly of data: J Hoevelmann, L Hähnle, J Hähnle, C Viljoen; (V) Data analysis and interpretation: All authors; (VI) Manuscript \\ writing: All authors; (VII) Final approval of manuscript: All authors. \\ \#These authors contributed equally to this work. \\ Correspondence to: Dr. Charle Viljoen. Division of Cardiology, Groote Schuur Hospital, University of Cape Town, Cape Town, South Africa. \\ Email: charle.viljoen@uct.ac.za.
}

\begin{abstract}
Peripartum cardiomyopathy (PPCM) is an idiopathic dilated cardiomyopathy, in which previously healthy women present with heart failure secondary to left ventricular (LV) systolic dysfunction during the last months of pregnancy or up to 5 months postpartum. PPCM occurs worldwide. The incidence seems to be increasing, possibly due to increasing awareness of the condition and diagnosis thereof. Women diagnosed with PPCM present with symptoms and signs of heart failure, thromboembolism or arrhythmia. Although the incidence of arrhythmias in this condition is not well documented, patients with PPCM often have rhythm disturbances. Indeed, life-threating arrhythmias contribute significantly to sudden cardiac death (SCD) in this population, especially when patients have poor systolic function. In this review, we summarize the evidence on atrial and ventricular arrhythmias in PPCM, as detected by various diagnostic modalities. Furthermore, we summarize the management of arrhythmias in PPCM, as recommended by contemporary guidelines.
\end{abstract}

Keywords: Ambulatory electrocardiographic monitoring (AECG); arrhythmia; cardioverter-defibrillator; electrocardiogram (ECG); peripartum cardiomyopathy (PPCM)

Submitted Apr 24, 2019. Accepted for publication May 20, 2019.

doi: $10.21037 / \mathrm{cdt} .2019 .05 .03$

View this article at: http://dx.doi.org/10.21037/cdt.2019.05.03

\section{Introduction}

Peripartum cardiomyopathy (PPCM) is a rare, idiopathic dilated cardiomyopathy, presenting with heart failure secondary to left ventricular (LV) systolic dysfunction towards the end of pregnancy or up to five months postpartum (1). PPCM occurs worldwide. However, the incidence of PPCM varies between countries as well as between ethnic groups (2-5). Incidence seems to be increasing, possibly due to increased awareness of the condition and the diagnosis thereof (6).

Even though the exact pathophysiology of PPCM is unknown, various mechanisms have been proposed to contribute to the pathogenesis. These include nutritional factors, viral infections, inflammatory and autoimmune processes, as well as a familial and genetic predisposition (7). Recent studies suggest that the nursing hormone prolactin is crucially involved in the pathogenesis of PPCM (8).

LV recovery in PPCM remains markedly heterogenous and differs significantly between countries and ethnicities. Recent reports suggest that approximately $45-75 \%$ of all affected women recover their LV function after 6 to 12 months. However, lower rates of recovery have been reported in developing countries (9). Although LV recovery predominantly occurs within the first 6 months after diagnosis, it has been shown to continue beyond 


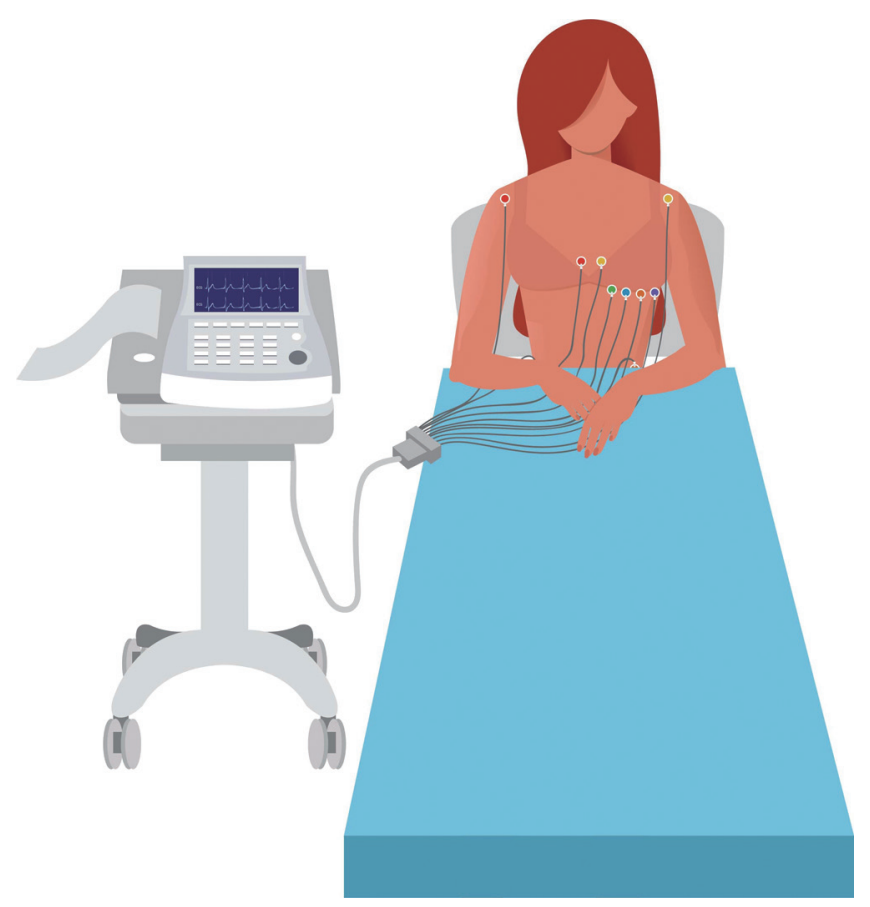

Figure 1 The 12-lead electrocardiogram forms part of the routine work-up of all patients who are diagnosed with peripartum cardiomyopathy. The test is non-invasive, widely available, inexpensive and easily performed.

12 months (10). African ethnicity seems to have an impact on the outcome of patients with PPCM, as it has been shown that women of African ethnicity present with a more severely reduced LV ejection fraction (LVEF) and recover less frequently than their non-African counterparts (11).

Sudden cardiac death (SCD), which is often the result of a preceding episode of a ventricular tachyarrhythmia, is responsible for about one-third of deaths in non-ischaemic cardiomyopathies (NICM) (12). In PPCM, SCD contributes to $25-39 \%$ of all-cause mortality $(13,14)$, suggesting that arrhythmias are not uncommon in this population (15). Indeed, in a retrospective analysis of 9,841 hospital admissions for PPCM in the USA, arrhythmias were reported to have occurred in $18.7 \%$ of cases. In this study, ventricular tachycardia (VT) - seen in $4.2 \%$ of patientswas the most common arrhythmia, followed by atrial fibrillation (1.3\%) and ventricular fibrillation (VF) (1\%) (16). However, literature on the exact underlying mechanisms of SCD in the course of PPCM is scarce, particularly that pertaining to the burden of malignant ventricular arrhythmias. Nevertheless, studies show that reduced LVEF in the early stages of PPCM is accompanied by a high risk of life-threatening ventricular arrhythmias, which may lead to SCD if left untreated $(17,18)$. In this regard, Goland et al. estimated that in the USA 1 in 4 women with PPCM suffer cardiac arrest secondary to ventricular tachyarrhythmia (14).

In this review, we explore the methods of detecting and diagnosing arrhythmias in PPCM, which may ultimately assist in the risk stratification and in decision of appropriate therapy. We also summarise the management of arrhythmias in PPCM, as recommended by contemporary guidelines.

\section{2-lead electrocardiogram (ECG)}

The 12-lead ECG (Figure 1) is an inexpensive, easily performed and widely available clinical investigation, which forms part of the routine work-up of patients who present with cardiovascular disease (Table 1). Indeed, the ECG is recommended in all patients who present with a suspected diagnosis of PPCM (27). The 12-lead ECG is invaluable for the analysis of waveform abnormalities that are associated with chamber enlargement (such as atrial dilatation or ventricular hypertrophy), conduction delays (such as bundle branch blocks) and repolarization abnormalities (such as $\mathrm{T}$ wave inversion and prolonged QT intervals) (28). The 12lead ECG is also indispensable as a diagnostic modality of brady- and tachyarrhythmias.

Although there is no specific electrocardiographic abnormality that is pathognomonic of PPCM, women with PPCM rarely have a normal ECG $(19,20)$. The most common waveform abnormalities seen on the 12-lead ECG include non-specific $\mathrm{T}$ wave changes (i.e., $\mathrm{T}$ wave inversion) and prolongation of the QTc interval (Table 2) (19-21,29,33). $T$ wave inversion at the time of diagnosis is associated with poor systolic function (LVEF <35\%) (20). Furthermore, an upright $\mathrm{T}$ wave in lead aVR has recently been shown to be a predictor of adverse outcome in PPCM (31). In another prospective study, QTc prolongation (i.e., corrected QT interval $>460 \mathrm{~ms}$ ) on the initial ECG was shown to be an independent predictor of poor long-term outcome in PPCM. In fact, all patients who died in this study initially presented with a prolonged QTc interval (20). Care should therefore be taken when treating patients with PPCM to avoid drugs that are associated with QT prolongation.

Despite the QRS complex of patients with PPCM being marginally wider than that of a healthy population (21), it is typically narrow (i.e., QRS $<110 \mathrm{~ms})(20,22,29)$. As opposed to other forms of dilated cardiomyopathy where bundle branch blocks are encountered in $25-30 \%$ of patients $(34,35)$, bundle branch blocks are seldom found in 
Table 1 Comparison of devices used to diagnose arrhythmias, with supporting evidence of the atrial and ventricular arrhythmias found in PPCM

\begin{tabular}{|c|c|c|c|c|c|}
\hline & ECG & \multicolumn{2}{|c|}{ Ambulatory ECG monitoring } & \multicolumn{2}{|c|}{ Cardioverter-defibrillator devices } \\
\hline $\begin{array}{l}\text { Length of } \\
\text { recording }\end{array}$ & 10 seconds & $\begin{array}{l}\text { Usually } 24 \text { or } \\
48 \text { hours, though } \\
\text { newer devices can } \\
\text { monitor up to } \\
60 \text { days }\end{array}$ & $\begin{array}{l}\text { Up to } \\
\text { three years } \\
\text { (depending on } \\
\text { the battery leave } \\
\text { of the device) }\end{array}$ & $\begin{array}{l}\text { As long as wearable } \\
\text { cardioverter-defibrillator } \\
\text { is worn }\end{array}$ & $\begin{array}{l}\text { As long as battery } \\
\text { life of implanted } \\
\text { cardioverter- } \\
\text { defibrillator lasts }\end{array}$ \\
\hline $\begin{array}{l}\text { Purpose of } \\
\text { device }\end{array}$ & Diagnostic & Diagnostic & Diagnostic & $\begin{array}{l}\text { Therapeutic, but also } \\
\text { provides diagnostic } \\
\text { information }\end{array}$ & $\begin{array}{l}\text { Therapeutic, but } \\
\text { also provides } \\
\text { diagnostic } \\
\text { information }\end{array}$ \\
\hline
\end{tabular}

ECG, electrocardiogram; LBBB, left bundle branch block; LVEF, left ventricular ejection fraction; PPCM, peripartum cardiomyopathy; QTc, corrected QT interval; SCD, sudden cardiac death; SVT, supraventricular tachycardia; VT, ventricular tachycardia. 
Table 2 Summary of prospective and retrospective studies diagnosing arrhythmias in PPCM

\begin{tabular}{|c|c|c|c|c|c|c|c|c|c|}
\hline \multirow{2}{*}{ Author } & \multirow{2}{*}{ Year } & \multirow{2}{*}{ Country } & \multirow{2}{*}{$\mathrm{N}$} & \multirow{2}{*}{ Main finding about arrhythmias in PPCM } & \multicolumn{5}{|c|}{ Arrhythmias diagnosed with } \\
\hline & & & & & ECG & Holter & ILR & WCD & ICD \\
\hline \multicolumn{10}{|l|}{ Prospective studies } \\
\hline $\begin{array}{l}\text { Duncker } \\
\text { et al. (17) }\end{array}$ & 2014 & Germany & 12 & $\begin{array}{l}9 \text { of } 12 \text { patients had LVEF }<35 \% \text {; in } 3 \text { of } 7 \text { patients } \\
\text { with WCD, ventricular tachyarrhythmias were } \\
\text { detected and successfully treated by the device }\end{array}$ & & & & $x$ & \\
\hline $\begin{array}{l}\text { Duncker } \\
\text { et al. (18) }\end{array}$ & 2017 & Germany & 49 & $\begin{array}{l}\text { All patients had LVEF }<35 \% \text { and fitted with WCD. } \\
\text { Of these } 12 \% \text { had ventricular tachyarrhythmias with } \\
\text { appropriate therapy by the device }\end{array}$ & & & & $x$ & \\
\hline $\begin{array}{l}\text { Hoevelmann } \\
\text { et al. (20) }\end{array}$ & 2019 & SA & 66 & $\begin{array}{l}\text { Prolonged QTC and sinus tachycardia were } \\
\text { independent predictors of poor outcome. Sinus } \\
\text { arrhythmia was associated with event-free survival }\end{array}$ & $x$ & & & & \\
\hline Karaye et al. (21) & 2016 & Nigeria & 54 & $\begin{array}{l}54 \text { patients with PPCM were compared with } 77 \\
\text { healthy controls. QTc prolongation was found in } \\
\text { almost } 25 \% \text { of those with PPCM }\end{array}$ & $x$ & & & & \\
\hline Ntusi et al. (23) & 2015 & SA & 30 & $\begin{array}{l}30 \text { patients with PPCM were compared to } \\
53 \text { patients with hypertensive heart failure of } \\
\text { pregnancy. Atrial fibrillation was found in } 10 \% \text { of } \\
\text { patients with PPCM }\end{array}$ & $x$ & & & & \\
\hline $\begin{array}{l}\text { Pillarisetti } \\
\text { et al. }(30)\end{array}$ & 2014 & USA & 100 & $\begin{array}{l}2 \text { patients died from arrhythmia-related causes } \\
\text { (unspecified) }\end{array}$ & $?$ & & & & \\
\hline $\begin{array}{l}\text { Saltzberg } \\
\text { et al. (25) }\end{array}$ & 2012 & USA & 107 & $\begin{array}{l}107 \text { patients with PPCM were compared with } 109 \\
\text { other non-dilated ischaemic cardiomyopathies. } \\
\text { None of the patients with PPCM experienced any } \\
\text { arrhythmic events }\end{array}$ & & & & $x$ & \\
\hline \multicolumn{10}{|c|}{ Retrospective studies } \\
\hline $\begin{array}{l}\text { De Benedetti } \\
\text { Zunino et al. (26) }\end{array}$ & 2014 & USA & 19 & $\begin{array}{l}\text { ICD for primary prevention: } 37 \% \text { of patients had } \\
\text { appropriate shocks }\end{array}$ & & & & & $x$ \\
\hline Ekizler et al. (31) & 2019 & Turkey & 82 & $\begin{array}{l}\text { An upright } T \text { wave in lead aVR on ECG was } \\
\text { associated with poor outcome }\end{array}$ & $x$ & & & & \\
\hline Goland et al. (14) & 2009 & USA & 46 & $\begin{array}{l}15 \% \text { had ventricular tachyarrhythmias requiring ICD; } \\
7 \% \text { had bradyarrhythmias requiring pacemakers }\end{array}$ & $?$ & & & & \\
\hline Laghari et al. (32) & 2013 & Pakistan & 45 & $\begin{array}{l}6.6 \% \text { of patients presented with ventricular } \\
\text { tachycardia }\end{array}$ & $?$ & & & & \\
\hline Li et al. (33) & 2016 & China & 71 & $\begin{array}{l}\text { QTc prolongation was found in } 47 \% \text { of PPCM } \\
\text { patients }\end{array}$ & $x$ & & & & \\
\hline $\begin{array}{l}\text { Mallikethi-Reddy } \\
\text { et al. (16) }\end{array}$ & 2017 & USA & 9841 & $\begin{array}{l}\text { Arrhythmias were present in } 18.7 \% \text { of hospitalized } \\
\text { PPCM cohort. } 4.2 \% \text { had VT, } 2.2 \% \text { had sudden } \\
\text { cardiac death }\end{array}$ & $?$ & & & & \\
\hline
\end{tabular}

ECG, electrocardiogram; ICD, implantable cardioverter-defibrillator; ILR, implantable loop recorder; LVEF, left ventricular ejection fraction; PPCM, peripartum cardiomyopathy; PVC, premature ventricular complex; QTc, corrected QT interval; VT, ventricular tachycardia; WCD, wearable cardioverter-defibrillator; SA, South Africa; USA, the United States of America. 


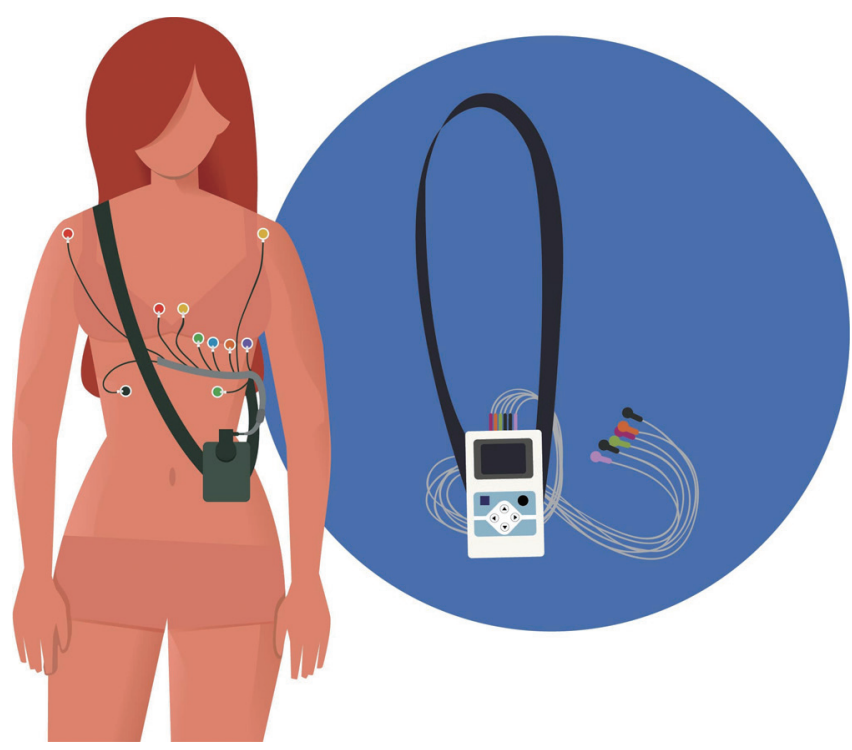

Figure 2 The Holter ECG is a form of continuous ambulatory ECG monitoring, which typically records data for 24 to 48 hours. The Holter ECG has a good yield of arrhythmias, but only if they occur frequently. ECG, electrocardiogram.

PPCM $(20,22)$. Though the literature on bradyarrhythmias in PPCM is scarce, it has been reported that up to $7 \%$ of patients require permanent pacing (14).

The majority of patients with PPCM present with sinus rhythm. Though sinus tachycardia (i.e., sinus rhythm with heart rate $>100$ beats per minute) is frequently found at the time of diagnosis, there seems to be a significant reduction in heart rate between the initial presentation with PPCM and subsequent follow-up visits $(20,22)$. Sinus arrhythmia (i.e., sinus rhythm with variable RR intervals), which occurs in about one third of patients at the time of their PPCM diagnosis, becomes more prevalent at long-term followup (20). Whereas sinus tachycardia at the time of diagnosis has been shown to be an independent predictor of poor long-term outcome in PPCM, sinus arrhythmia seems to be associated with event-free survival (i.e., no death or readmission to hospital) (20).

Although atrial fibrillation is more prevalent in PPCM than in hypertensive heart failure of pregnancy (23), it remains relatively uncommon (20,31). Supraventricular and ventricular tachycardia are rarely are rarely recorded by the 12-lead ECG in patients with PPCM $(16,20,29)$. However, as the 12-lead ECG usually only records a 'snapshot' of 10 seconds, it is thought that the true incidence of these bradyand tachyarrhythmias is underestimated by studies that include the 12-lead ECG as the only method of diagnosing arrhythmias in PPCM.

\section{Ambulatory ECG monitoring}

Ambulatory electrocardiographic monitoring (AECG) is essential in the work-up of arrhythmias, especially when arrhythmias and/or symptoms are paroxysmal (36). Because ambulatory ECG monitoring extends the recording time significantly from the 10-second long 12-lead ECG, it allows for a more accurate characterization of cardiac activity during ordinary daily activities and increases the yield of arrhythmias (36,37).

AECG devices can be categorized according to whether they record continuously (over a shorter period of time) or intermittently (with brief recordings over an extended period of time) (37). Continuous AECG monitoring is commonly referred to as "Holter" ECG monitoring (Figure 2). Holter monitors are non-invasive and are usually worn for a period of 24 to 48 hours $(38,39)$, though newer technology allows monitoring for up to 60 days (40). Holter monitoring is more likely to detect arrhythmias if symptoms and/ or arrhythmias occur frequently. However, intermittent AECG monitoring allows for longer periods of surveillance. Intermittent AECG devices include external loop recorders (i.e., an adhesive electrode that is usually worn for up to two months) and implantable loop recorders (ILR) (i.e., a monitoring device that is implanted subcutaneously) (Figure 3). Due to recent advances, newer ILR devices are smaller in size and have improved algorithms for arrhythmia detection (Figure 4) (41). Although loop recorders are worn continuously, they only record when the device detects an arrhythmia or when patients activate the device when symptomatic. Because of their extended monitoring, loop recorders are more likely to detect intermittent or infrequent arrhythmias (40).

Literature on ambulatory ECG monitoring in PPCM is limited to a single study by Diao et al., who prospectively studied the detection of arrhythmias by 24-hour Holter in a cohort of 19 patients with PPCM (24). Though infrequent symptoms impede the detection rate of arrhythmias by Holter monitoring (38), the 24-hour Holter recorded VT in 4 of 19 the patients (21\%) in this cohort (24).

Similarly, the 12-lead ECG does not often record premature atrial or ventricular contractions in PPCM (20), but these were more frequently diagnosed by Holter monitoring, i.e., premature atrial contractions in $21 \%$ and 
premature ventricular contractions in $36.8 \%$ of patients in the study by Diao et al. (24). The significance of detection of premature complexes by AECG in PPCM has not yet been studied.

In addition to the detection of arrhythmias, Holter monitoring also provides useful information regarding heart rate. The ambulatory monitoring device's software typically

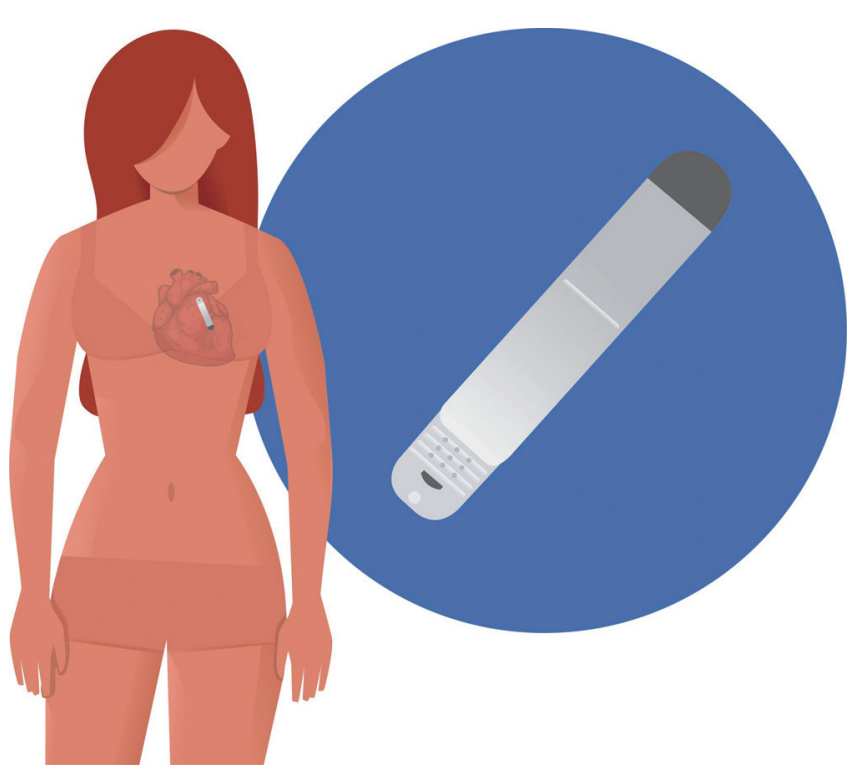

Figure 3 The implantable loop recorder (ILR) is a form of intermittent ambulatory ECG monitoring, which is implanted subcutaneously and can record up to 3 years' data. ILRs should be considered when arrhythmias are thought to occur infrequently and when the Holter ECG is non-revealing. ECG, electrocardiogram. provides the average heart rate over the monitoring period, as well as the minimum and maximum heart rates, and the time spent in bradycardia and tachycardia over the period that the Holter ECG was worn by the patient $(36,40)$. In their study, Diao et al. demonstrated that Holter monitoring was more sensitive at diagnosing sinus tachycardia: the 24-hour Holter detected sinus tachycardia in $89.4 \%$ of patients with PPCM, whereas the 12-lead ECG recorded sinus tachycardia in only $68.4 \%$ of patients from the same cohort (24). Diagnosing sinus tachycardia may have implications on risk stratification of patients with PPCM, as sinus tachycardia on the 12-lead ECG has been shown to be associated with poor long-term outcome (20).

As SCD significantly contributes to mortality in PPCM, and recognizing the shortage of literature on ECG monitoring beyond that of the 12-lead ECG, future research should include AECG in prospective studies to establish the true incidence of arrhythmias in PPCM. At present, there is an ongoing study with an ILR for the early identification of patients with PPCM at risk for arrhythmic events.

\section{Prevention and treatment of arrhythmias in PPCM}

The management of arrhythmias in PPCM requires the concurrent treatment of systolic heart failure. The essential therapies for acute PPCM can be summarized with the acronym 'BOARD' (Bromocriptine, Oral heart failure therapies, Anticoagulants, vasoRelaxing agents, and Diuretics) (42). As outlined in the European Society of Cardiology (ESC) Guidelines (43), therapeutic management

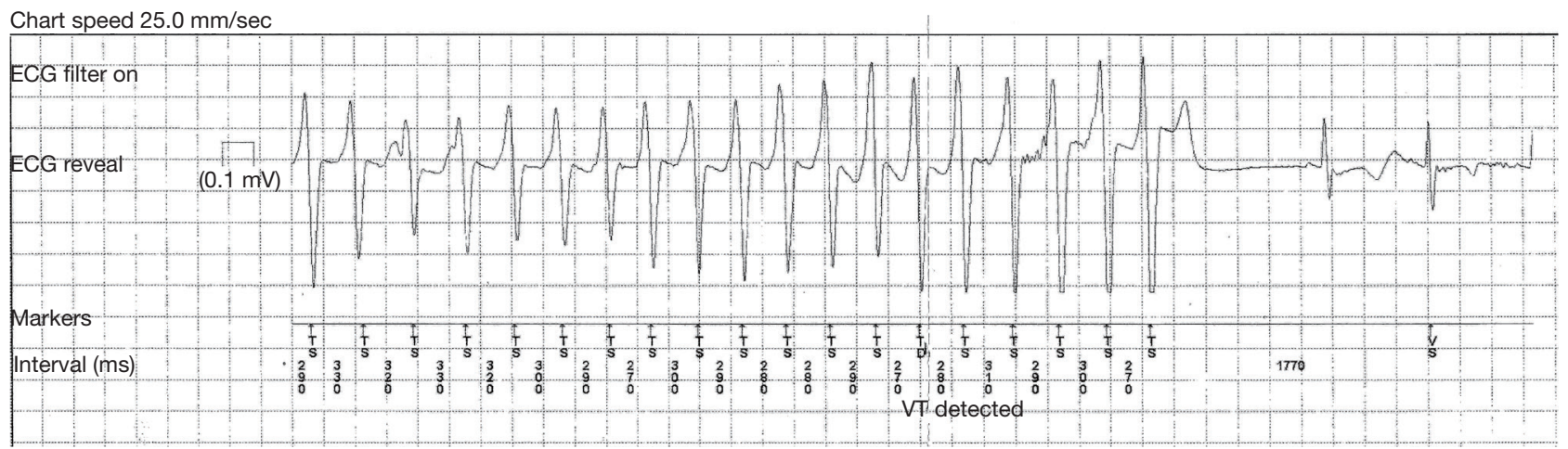

Figure 4 An episode of non-sustained ventricular tachycardia (VT) as recorded by an implantable loop recorder in a patient with peripartum cardiomyopathy. The non-sustained VT is recognised by the wide QRS complexes with short RR intervals (on the left). The last two beats (on the right) represent sinus rhythm with narrow QRS complexes. 
of acute PPCM differs depending on the severity of heart failure, and whether the patient presents during the antepartum or postpartum period.

In the antepartum period, patients with PPCM are best co-managed by a team consisting of cardiologists and obstetricians to ensure the health of the mother and the foetus. Due to the risk of fetotoxic side-effects, treatment such as angiotensin converting enzyme inhibitors (ACE-i), angiotensin II receptor blockers (ARB), angiotensin receptor-neprilysin inhibitors (ARNI) and mineralocorticoid receptor antagonists (MRA) should rather be avoided during pregnancy. However, hydralazine and nitrates have been shown to be safer in the antepartum period instead. Loop diuretics could be considered for the treatment of pulmonary congestion and vaginal delivery should be pursued in patients without cardiopulmonary distress. Beta-blockers (i.e., metoprolol as preferred agent) could be initiated but the doses should be titrated with caution $(27,43)$.

After delivery, treatment of PPCM should be aligned with contemporary acute and chronic heart failure guidelines (27,44-46). First-line therapy should consist of a combination of beta-blockers, ACE-i/ARBs, an MRA and diuretics. The benefits of using digoxin in addition to first-line therapy remains controversial (47). The use of the prolactin-blocker, bromocriptine, should be considered, and should be accompanied by anticoagulants to reduce the risk of thromboembolic events (27).

As sinus tachycardia is associated with adverse outcome in PPCM, ivabradine may be considered in addition to firstline therapy in patients with an increased resting heart rate who are not pregnant or breastfeeding $(27,43)$. However, evidence supporting the use of ivabradine in this setting is currently limited to a single retrospective observational study (48).

When a patient with PPCM develops atrial fibrillation, beta-blockers and/or digoxin could be considered. Because amiodarone is associated with foetal side effects, it should be reserved for emergency situations. Electrical cardioversion is only indicated in the setting of haemodynamic instability $(43,49)$.

Patients with PPCM who present with sustained VT or VF should be electrically cardioverted or defibrillated without delay $(43,50)$. Intravenous amiodarone may be considered in patients with refractory VT $(43,50)$.

\section{Implantable cardioverter-defibrillator (ICD)}

Patients with severely impaired systolic function (LVEF $<35 \%$ ) are at high risk of life-threatening ventricular arrhythmias, which could result in SCD $(51,52)$. The current ESC guidelines on acute and chronic heart failure therefore recommend ICD implantation as primary prevention in patients with severely reduced ejection fraction (i.e., LVEF $<35 \%)$ despite optimal medical therapy (OMT) and as secondary prevention in patients with a documented or survived episode of ventricular arrhythmias (44). Indeed, in a retrospective analysis of 19 patients with PPCM that received ICDs for primary prevention of SCD, $36.8 \%$ received appropriate shocks (26). However, given the high LV recovery rate associated with PPCM, the decision to implant an ICD should be made with caution. Early implantation of ICDs is often not justifiable in this young population and it has therefore been suggested that, in PPCM, they should be reserved for patients without LV recovery $(27,43)$.

\section{Wearable cardioverter-defibrillator (WCD)}

A WCD (LifeVest ${ }^{\circledR}$, Zoll, Pittsburgh, PA, USA) is a safe and non-invasive device, which can protect from SCD during a suspected, vulnerable period for arrhythmic events. The vest continuously analyzes the heart rhythm and delivers biphasic shocks once a life-threatening arrhythmia is detected (53). Although these devices primarily have a therapeutic indication, they also offer important diagnostic information. A recent study from Germany evaluated the use of a WCD for prevention of SCD in PPCM in PPCM (Figure 5). During a cumulated wearing time of 932 days, four adequate shocks were delivered by the WCD for VF to the seven patients with newly diagnosed PPCM and severely reduced ejection fraction (LVEF $<35 \%$ ) who opted to wear the WCD (17). In a subsequent study on 49 patients with newly diagnosed PPCM and severely reduced ejection fraction (LVEF <35\%), the WCD recorded ventricular arrhythmias in six patients (12\%), i.e., five episodes of VF, two sustained VTs and one non-sustained VT. All episodes of VF were terminated by a WCD shock and no inappropriate shocks occurred during the study period. These ventricular arrhythmias occurred between 40 and 165 days after the diagnosis of PPCM was made and the WCD was fitted (18). 


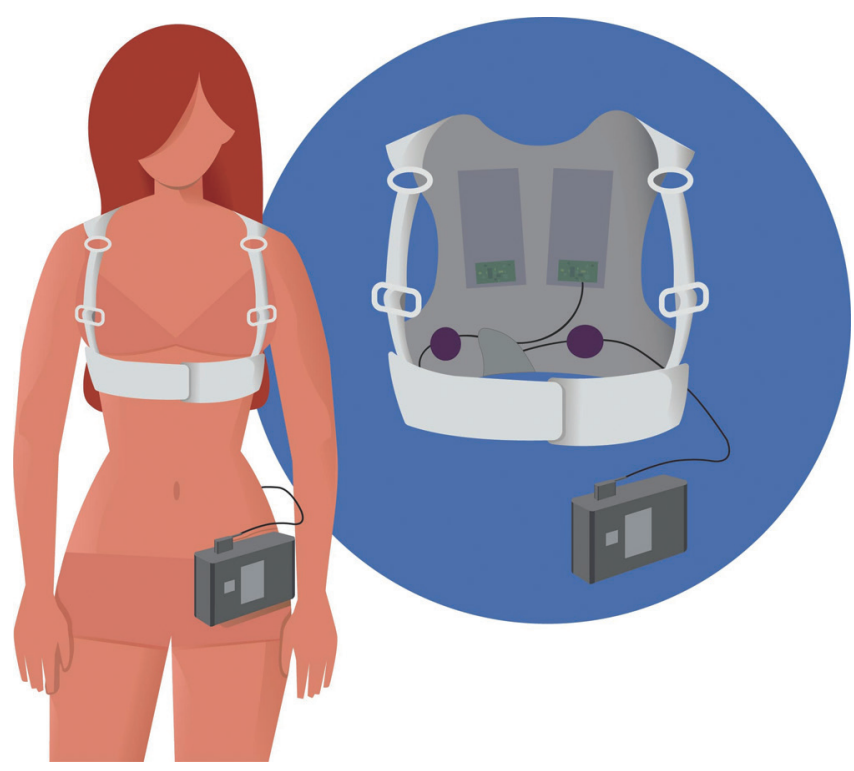

Figure 5 The wearable cardioverter-defibrillator (WCD) is a noninvasive device that is worn by patients with $\mathrm{LVEF}<35 \%$. The WCD is able to deliver biphasic shocks when a life-threatening arrhythmia is detected and could be used as a 'bridging' strategy during the first 6 months of vulnerability to sudden cardiac death in PPCM, before a final decision towards implantable cardioverterdefibrillator (ICD) is made. PPCM, peripartum cardiomyopathy; LVEF, left ventricular ejection fraction.

Despite the limited evidence on WCD in PPCM, the current European and American guidelines suggest consideration of these devices for high-risk patients with LVEF $\leq 35 \%$ as a 'bridging strategy' to LV recovery $(27,43)$. Bearing in mind that a WCD could save the life of a young mother, the high costs of the vest could be justifiable; especially given its reusability. ICD implantation (Figure 6) and cardiac resynchronization therapy (CRT) [for patients with LBBB (left bundle branch block) and QRS duration $\geq 130 \mathrm{~ms}$ ] should be reserved for patients with persistent LV dysfunction (LVEF <35\%) despite OMT at 6 to 12 months after presentation $(43,54)$.

\section{Conclusions}

The 12-lead ECG commonly shows repolarisation changes such as T wave inversion and QT prolongation. However, arrhythmias other than sinus tachycardia are infrequently detected by the 12-lead ECG. Though there is limited literature on ambulatory ECG monitoring in PPCM, it has

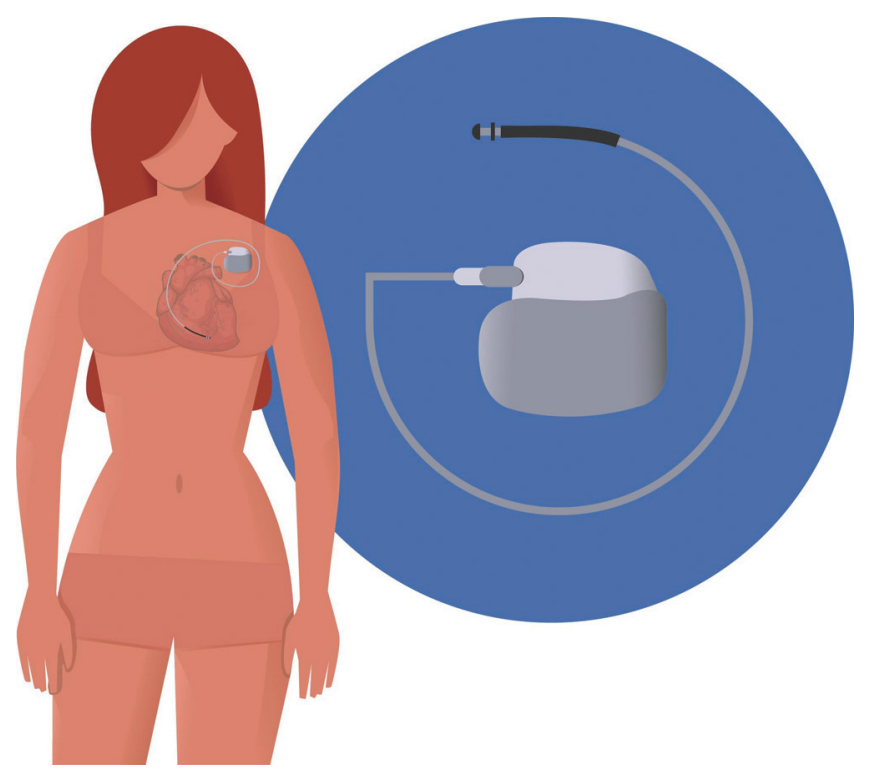

Figure 6 The implantable cardioverter defibrillator (ICD) delivers shocks when life-threatening arrhythmias are detected. In PPCM, ICD therapy is best reserved for patients without LV recovery (usually LVEF <35\%) at follow-up. PPCM, peripartum cardiomyopathy; LV, left ventricular; LVEF, left ventricular ejection fraction.

been shown that life-threatening ventricular arrhythmias might be relatively common in the early phase of the condition. Because LV recovery is common in PPCM, the decision to insert an ICD in a patient who initially presents with an LVEF $<35 \%$ could be delayed, and a WCD could be considered instead. The WCD could be used as 'bridging therapy' until the LVEF is re-evaluated at follow up. ICDs are best reserved for patients with PPCM without $\mathrm{LV}$ recovery after 6 months.

\section{Acknowledgments}

We would like to thank Ms Helene-Marie Guillaume for designing the figures, as well as Associate Professor Ashley Chin from Groote Schuur Hospital in Cape Town, Mrs Sylvia Dennis from the Hatter Institute for Cardiovascular Research in Africa, and Dr. Nick Simpson at New Somerset Hospital in Cape Town, for their help in preparing the manuscript.

Funding: The Hatter Institute for Cardiovascular Research in Africa receives research funding and support from the University of Cape Town, the Medical Research Council (MRC) of South Africa and the South African National 
Research Foundation (NRF).

\section{Footnote}

Provenance and Peer Review: This article was commissioned by the Guest Editor (Ntobeko A. B. Ntusi) for the series "Cardiovascular Diseases in Low-and Middle-Income Countries" published in Cardiovascular Diagnosis and Therapy. The article was sent for external peer review organized by the Guest Editor and the editorial office.

Conflicts of Interest: All authors have completed the ICMJE uniform disclosure form (available at http://dx.doi. org/10.21037/cdt.2019.05.03). The series "Cardiovascular Diseases in Low-and Middle-Income Countries" was commissioned by the editorial office without any funding or sponsorship. The authors have no conflicts of interest to declare.

Ethical Statement: The authors are accountable for all aspects of the work in ensuring that questions related to the accuracy or integrity of any part of the work are appropriately investigated and resolved.

Open Access Statement: This is an Open Access article distributed in accordance with the Creative Commons Attribution-NonCommercial-NoDerivs 4.0 International License (CC BY-NC-ND 4.0), which permits the noncommercial replication and distribution of the article with the strict proviso that no changes or edits are made and the original work is properly cited (including links to both the formal publication through the relevant DOI and the license). See: https://creativecommons.org/licenses/by-nc-nd/4.0/.

\section{References}

1. Sliwa K, Hilfiker-Kleiner D, Petrie MC, et al. Current state of knowledge on aetiology, diagnosis, management, and therapy of peripartum cardiomyopathy: a position statement from the Heart Failure Association of the European Society of Cardiology Working Group on peripartum cardiomyopathy. Eur J Heart Fail 2010;12:767-78.

2. Isezuo SA, Abubakar SA. Epidemiologic profile of peripartum cardiomyopathy in a tertiary care hospital. Ethn Dis 2007;17:228-33.

3. Fett JD, Christie LG, Carraway RD, et al. Five-year prospective study of the incidence and prognosis of peripartum cardiomyopathy at a single institution. Mayo Clin Proc 2005;80:1602-6.

4. Desai D, Moodley J, Naidoo D. Peripartum cardiomyopathy: experiences at King Edward VIII Hospital, Durban, South Africa and a review of the literature. Trop Doct 1995;25:118-23.

5. Brar SS, Khan SS, Sandhu GK, et al. Incidence, mortality, and racial differences in peripartum cardiomyopathy. Am J Cardiol 2007;100:302-4.

6. Kolte D, Khera S, Aronow WS, et al. Temporal trends in incidence and outcomes of peripartum cardiomyopathy in the United States: a nationwide population-based study. J Am Heart Assoc 2014;3:e001056.

7. Hilfiker-Kleiner D, Sliwa K. Pathophysiology and epidemiology of peripartum cardiomyopathy. Nat Rev Cardiol 2014;11:364-70.

8. Hilfiker-Kleiner D, Kaminski K, Podewski E, et al. A cathepsin D-cleaved $16 \mathrm{kDa}$ form of prolactin mediates postpartum cardiomyopathy. Cell 2007;128:589-600.

9. Sliwa K, Petrie MC, Hilfiker-Kleiner D, et al. Longterm prognosis, subsequent pregnancy, contraception and overall management of peripartum cardiomyopathy: practical guidance paper from the Heart Failure Association of the European Society of Cardiology Study Group on Peripartum Cardiomyopathy. Eur J Heart Fail 2018;20:951-62.

10. Biteker M, Ilhan E, Biteker G, et al. Delayed recovery in peripartum cardiomyopathy: an indication for longterm follow-up and sustained therapy. Eur J Heart Fail 2012;14:895-901.

11. Irizarry OC, Levine LD, Lewey J, et al. Comparison of Clinical Characteristics and Outcomes of Peripartum Cardiomyopathy Between African American and NonAfrican American Women. JAMA Cardiol 2017;2:1256-60.

12. Pathak RK, Sanders P, Deo R. Primary prevention implantable cardioverter-defibrillator and opportunities for sudden cardiac death risk assessment in non-ischaemic cardiomyopathy. Eur Heart J 2018;39:2859-66.

13. Sliwa K, Forster O, Libhaber E, et al. Peripartum cardiomyopathy: inflammatory markers as predictors of outcome in 100 prospectively studied patients. Eur Heart J 2006;27:441-6.

14. Goland S, Modi K, Bitar F, et al. Clinical profile and predictors of complications in peripartum cardiomyopathy. J Card Fail 2009;15:645-50.

15. Arany Z, Elkayam U. Peripartum Cardiomyopathy. Circulation 2016;133:1397-409.

16. Mallikethi-Reddy S, Akintoye E, Trehan N, et al. Burden 
of arrhythmias in peripartum cardiomyopathy: Analysis of 9841 hospitalizations. Int J Cardiol 2017;235:114-7.

17. Duncker D, Haghikia A, Konig T, et al. Risk for ventricular fibrillation in peripartum cardiomyopathy with severely reduced left ventricular function-value of the wearable cardioverter/defibrillator. Eur J Heart Fail 2014;16:1331-6.

18. Duncker D, Westenfeld R, Konrad T, et al. Risk for lifethreatening arrhythmia in newly diagnosed peripartum cardiomyopathy with low ejection fraction: a German multi-centre analysis. Clin Res Cardiol 2017;106:582-9.

19. Tibazarwa K, Lee G, Mayosi B, et al. The 12-lead ECG in peripartum cardiomyopathy. Cardiovasc J Afr 2012;23:322-9.

20. Hoevelmann J, Viljoen CA, Manning K, et al. The prognostic significance of the 12-lead ECG in peripartum cardiomyopathy. Int J Cardiol 2019;276:177-84.

21. Karaye KM, Lindmark K, Henein MY. Electrocardiographic predictors of peripartum cardiomyopathy. Cardiovasc J Afr 2016;27:66-70.

22. Sliwa K, Mebazaa A, Hilfiker-Kleiner D, et al. Clinical characteristics of patients from the worldwide registry on peripartum cardiomyopathy (PPCM): EURObservational Research Programme in conjunction with the Heart Failure Association of the European Society of Cardiology Study Group on PPCM. Eur J Heart Fail 2017;19:1131-41.

23. Ntusi NB, Badri M, Gumedze F, et al. PregnancyAssociated Heart Failure: A Comparison of Clinical Presentation and Outcome between Hypertensive Heart Failure of Pregnancy and Idiopathic Peripartum Cardiomyopathy. PLoS One 2015;10:e0133466.

24. Diao M, Diop IB, Kane A, et al. Electrocardiographic recording of long duration (Holter) of 24 hours during idiopathic cardiomyopathy of the peripartum. Arch Mal Coeur Vaiss 2004;97:25-30.

25. Saltzberg MT, Szymkiewicz S, Bianco NR. Characteristics and outcomes of peripartum versus nonperipartum cardiomyopathy in women using a wearable cardiac defibrillator. J Card Fail 2012;18:21-7.

26. De Benedetti Zunino ME, Schuger C, Lahiri M. High Rate of Ventricular Arrhythmias in Women with Peripartum Cardiomyopathy and Implanted Cardioverter Defibrillators. J Am Coll Cardiol 2014. doi: 10.1016/ S0735-1097(14)60313-2.

27. Bauersachs J, Arrigo M, Hilfiker-Kleiner D, et al. Current management of patients with severe acute peripartum cardiomyopathy: practical guidance from the Heart Failure
Association of the European Society of Cardiology Study Group on peripartum cardiomyopathy. Eur J Heart Fail 2016;18:1096-105.

28. Okreglicki A, Scott Millar R. ECG: PQRST morphologyclues and tips. SA Heart Journal 2006;3:27-36.

29. Honigberg MC, Elkayam U, Rajagopalan N, et al. Electrocardiographic findings in peripartum cardiomyopathy. Clin Cardiol 2019;42:524-9.

30. Pillarisetti J, Kondur A, Alani A, et al. Peripartum cardiomyopathy: predictors of recovery and current state of implantable cardioverter-defibrillator use. J Am Coll Cardiol 2014;63:2831-9.

31. Ekizler FA, Cay S, Kafes H, et al. The prognostic value of positive $T$ wave in lead aVR: A novel marker of adverse cardiac outcomes in peripartum cardiomyopathy. Ann Noninvasive Electrocardiol 2019;24:e12631.

32. Laghari AH, Khan AH, Kazmi KA. Peripartum cardiomyopathy: ten year experience at a tertiary care hospital in Pakistan. BMC Res Notes 2013;6:495.

33. Li W, Li H, Long Y. Clinical Characteristics and Longterm Predictors of Persistent Left Ventricular Systolic Dysfunction in Peripartum Cardiomyopathy. Can J Cardiol 2016;32:362-8.

34. Aleksova A, Carriere C, Zecchin M, et al. New-onset left bundle branch block independently predicts longterm mortality in patients with idiopathic dilated cardiomyopathy: data from the Trieste Heart Muscle Disease Registry. Europace 2014;16:1450-9.

35. Grimm W, Sharkova J, Funck R, et al. How Many Patients with Dilated Cardiomyopathy May Potentially Benefit from Cardiac Resynchronization Therapy? Pacing Clin Electrophysiol 2003;26:155-7.

36. Steinberg JS, Varma N, Cygankiewicz I, et al. 2017 ISHNE-HRS expert consensus statement on ambulatory ECG and external cardiac monitoring/telemetry. Ann Noninvasive Electrocardiol 2017. doi: 10.1111/ anec. 12447.

37. Crawford MH, Bernstein SJ, Deedwania PC, et al. ACC/ AHA guidelines for ambulatory electrocardiography. J Am Coll Cardiol 1999;34:912-48.

38. Kadish AH, Buxton AE, Kennedy HL, et al. ACC/AHA Clinical Competence Statement on Electrocardiography and Ambulatory Electrocardiography. Circulation 2001;104:3169-78.

39. Su L, Borov S, Zrenner B. 12-lead Holter electrocardiography. Review of the literature and clinical application update. Herzschrittmacherther Elektrophysiol 2013;24:92-6. 
40. Locati ET. New directions for ambulatory monitoring following 2017 HRS-ISHNE expert consensus. J Electrocardiol 2017;50:828-32.

41. Mond HG. The Spectrum of Ambulatory Electrocardiographic Monitoring. Heart Lung Circ 2017;26:1160-74.

42. Arrigo M, Blet A, Mebazaa A. Bromocriptine for the treatment of peripartum cardiomyopathy: welcome on BOARD. Eur Heart J 2017;38:2680-2.

43. Regitz-Zagrosek V, Roos-Hesselink JW, Bauersachs J, et al. 2018 ESC Guidelines for the management of cardiovascular diseases during pregnancy. Eur Heart J 2018;39:3165-241.

44. Ponikowski P, Voors AA, Anker SD, et al. 2016 ESC Guidelines for the diagnosis and treatment of acute and chronic heart failure: The Task Force for the diagnosis and treatment of acute and chronic heart failure of the European Society of Cardiology (ESC)Developed with the special contribution of the Heart Failure Association (HFA) of the ESC. Eur Heart J 2016;37:2129-200.

45. Bozkurt B, Colvin M, Cook J, et al. Current Diagnostic and Treatment Strategies for Specific Dilated Cardiomyopathies: A Scientific Statement From the American Heart Association. Circulation 2016;134:e579-646.

46. Yancy CW, Jessup M, Bozkurt B, et al. 2017 ACC/ AHA/HFSA Focused Update of the 2013 ACCF/AHA Guideline for the Management of Heart Failure: A Report of the American College of Cardiology/American Heart Association Task Force on Clinical Practice Guidelines and the Heart Failure Society of America. J Am Coll Cardiol 2017;70:776-803.

47. Cunningham FG, Byrne JJ, Nelson DB. Peripartum Cardiomyopathy. Obstet Gynecol 2019;133:167-79.

48. Haghikia A, Tongers J, Berliner D, et al. Early ivabradine treatment in patients with acute peripartum cardiomyopathy: Subanalysis of the German PPCM

Cite this article as: Hoevelmann J, Hähnle L, Hähnle J, Sliwa K, Viljoen C. Detection and management of arrhythmias in peripartum cardiomyopathy. Cardiovasc Diagn Ther 2020;10(2):325-335. doi: 10.21037/cdt.2019.05.03 registry. Int J Cardiol 2016;216:165-7.

49. Kirchhof P, Benussi S, Kotecha D, et al. 2016 ESC Guidelines for the management of atrial fibrillation developed in collaboration with EACTS. Eur Heart J 2016;37:2893-962.

50. Priori SG, Blomstrom-Lundqvist C, Mazzanti A, et al. 2015 ESC Guidelines for the management of patients with ventricular arrhythmias and the prevention of sudden cardiac death: The Task Force for the Management of Patients with Ventricular Arrhythmias and the Prevention of Sudden Cardiac Death of the European Society of Cardiology (ESC). Endorsed by: Association for European Paediatric and Congenital Cardiology (AEPC). Eur Heart J 2015;36:2793-867.

51. Goldberger JJ, Cain ME, Hohnloser SH, et al. American Heart Association/American College of Cardiology Foundation/Heart Rhythm Society Scientific Statement on Noninvasive Risk Stratification Techniques for Identifying Patients at Risk for Sudden Cardiac Death. A scientific statement from the American Heart Association Council on Clinical Cardiology Committee on Electrocardiography and Arrhythmias and Council on Epidemiology and Prevention. J Am Coll Cardiol 2008;52:1179-99.

52. Lip GY, Heinzel FR, Gaita F, et al. European Heart Rhythm Association/Heart Failure Association joint consensus document on arrhythmias in heart failure, endorsed by the Heart Rhythm Society and the Asia Pacific Heart Rhythm Society. Eur J Heart Fail 2015;17:848-74.

53. Duncker D, Veltmann C. The Wearable Cardioverter/ Defibrillator - Toy Or Tool? J Atr Fibrillation 2016;8:1367.

54. Al-Khatib SM, Stevenson WG, Ackerman MJ, et al. 2017 AHA/ACC/HRS Guideline for Management of Patients With Ventricular Arrhythmias and the Prevention of Sudden Cardiac Death: Executive Summary. Circulation 2018;138:e210-71. 